\title{
Research on building a smart supply chain system to promote the high-quality economic development of Guangdong, Hong Kong and Macao
}

\author{
Yonghui $\mathrm{CAO}^{1, \mathrm{a}}$, He JIANG ${ }^{2, b *}$ \\ ${ }^{1}$ Department of Business Administration, Guangzhou College of Technology and Business, Guangzhou, China \\ ${ }^{2}$ Department of Business Administration, Guangzhou College of Technology and Business, Guangzhou, China
}

\begin{abstract}
To promote the construction of Guangdong, Hong Kong and Macao Bay area is a major decision made by the Party Central Committee, a new measure to promote the formation of a new pattern of comprehensive opening-up in the new era, and a new practice to promote the development of the cause of "one country, two systems". Promoting the construction of the Great Bay area of Guangdong, Hong Kong and Macao is conducive to deepening exchanges and cooperation between the mainland and Hong Kong and Macao, and is of great significance for Hong Kong and Macao to participate in national development strategies, enhance competitiveness and maintain long-term prosperity and stability. From the perspective of smart supply chain, this paper proposes to build a smart supply chain system in Guangdong, Hong Kong and Macao to promote high-quality economic development.
\end{abstract}

\section{Introduction}

Promoting the construction of the Great Bay Area in Guangdong, Hong Kong and Macao is a major decision made by the Central Committee of the CPC Central Committee with Comrade Xi Jinping as the core. It is a national strategy of general secretary Xi Jinping himself, who plans, personally deploys and personally promote[1,2]. It is a new measure to promote the formation of a new pattern of comprehensive opening in the new era, and is also a new practice to promote the development of "one country two systems"[3,4]. Promoting the construction of the Great Bay area of Guangdong, Hong Kong and Macao is conducive to deepening exchanges and cooperation between the mainland and Hong Kong and Macao, and is of great significance for Hong Kong and Macao to participate in national development strategies, enhance competitiveness and maintain long-term prosperity and stability $[5,6]$.

At present, the economy of our province has entered a new period of high-quality development from the stage of high-speed growth. Economic development is faced with the problems of insufficient effective demand, low quality and efficiency of supply side system. The supply side structural reform, which focuses on capacity reduction, inventory reduction, leverage reduction, cost reduction, and weakness compensation, is a major strategic measure to enhance the driving force of sustained economic growth, solve deep-seated problems in economic development, and improve the quality of economic development. It has been proved that the smart supply chain has significant effect on promoting the supply side structural reform of our province in the aspects of inventory removal, cost reduction, solution of supply and demand dislocation, and promotion of industrial transformation and upgrading. The CPC Central Committee and the State Council attached great importance to the innovation and application of supply chain. Xi Jinping, general secretary of the CPC and Premier Li Keqiang put forward the optimization and innovation of supply chain on many occasions. According to the report of the 19th National Congress of the Communist Party of China, we should cultivate new growth points and form new momentum in the fields of middle and high-end consumption, innovation leading, green and low-carbon, sharing economy, modern supply chain, human capital service, etc. In October 2017, the guidance on promoting supply chain innovation and application issued by the general office of the State Council proposed that "by 2020, a smart supply chain system covering China's key industries will be basically formed" to accelerate the innovation and application of smart supply chain, which has become an important part of promoting supply side structural reform, cultivating new economic growth points and building a modern economic system. As smart supply chain is still a new theoretical concept, the related research at home and abroad is still in the primary stage[7]. According to the industry research report, the supply chain industry has an important impact on economic development, as shown below:

axinrui20132015@126.com; * Corresponding author: He JIANG;e-mail:b'GZhappy2020@126.com 
Table 1 impact of supply chain industry

\begin{tabular}{lll}
\hline Symbol & supply chain industry & Proportion \\
\hline $\mathrm{A}$ & $\begin{array}{l}\text { proportion of supply chain } \\
\text { industry in total fiscal revenue } \\
\text { and employment }\end{array}$ & $6 \%$ \\
\hline $\mathrm{B}$ & $\begin{array}{l}\text { impact of supply chain industry } \\
\text { on social economy and other } \\
\text { industries }\end{array}$ & $12 \%$ \\
\hline $\mathrm{C}$ & $\begin{array}{l}\text { competition and innovation } \\
\text { capacity of supply chain industry }\end{array}$ & $5 \%$ \\
\hline
\end{tabular}

In 2019, the scale of the supply chain industry will reach 240 billion Yuan, and the market speed will remain above $10 \%$ from 2011 to 2019 .

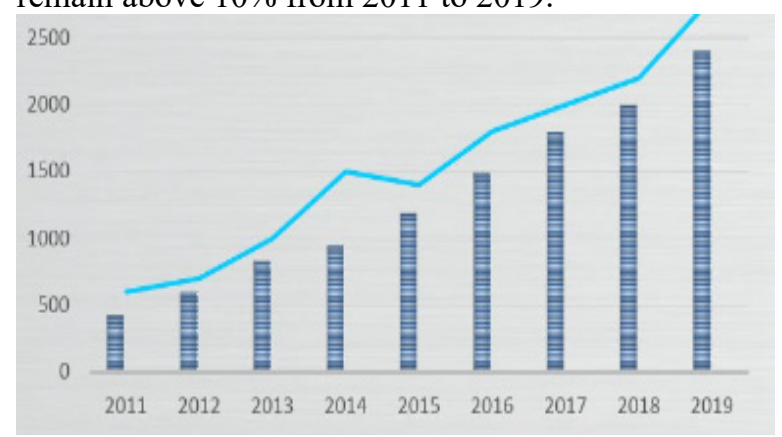

Figure 1 market changes of China's supply chain industry

\section{Review of research on smart supply chain at home and abroad}

\subsection{Research Trends of Foreign Smart Supply Chain}

The research of smart supply chain is just 10 years old, and it is still in its infancy. It was first proposed by IBM in 2008 that the smart supply chain is a part of IBM's smart earth. In 2009, IBM pointed out the five problems existing in the current supply chain, including cost control, supply chain visibility, risk management, increased user demand, globalization, etc. through the global chief supply chain officer survey report, and believed that the future supply chain should develop in the direction of advanced, interconnected and intelligent. Through the literature review, it can be seen that the research on smart supply chain in literature mainly focuses on four parts: information management of supply chain, Internet of things based on its technology, process automation and big data analysis, and has not yet formed a complete smart supply chain system.

For the information management in the smart supply chain, it is mainly focused on the demand (or order) information management between node enterprises. The research shows that intelligent supply chain manufacturing provides accurate, high-quality and timely information, and has controllability for information supply chain and protection. In the research of it based Internet of things, it is found that smart devices and sensors can greatly improve the visibility of supply chain, improve manufacturing efficiency and efficiency, reduce inventory, prevent out of stock, avoid inventory surplus and improve data accuracy, which is helpful to create unique value for all stakeholders in the supply chain. However, the research of intelligent supply chain in process automation mainly focuses on manufacturing, purchasing, warehouse, distribution and retail (Trebilcock, 2013). Research on big data believes that big data can create great value for the world economy, improve the productivity of companies and public sectors, and create a large amount of economic surplus for consumers. Barton \& Court (2012) pointed out that smart supply chain requires enterprises to obtain correct data, establish models to predict and optimize business output, and transform them into organizational processes. Among them, data mining is an important method to discover and interpret data patterns. In addition, some enterprises have tried and explored some ideas of smart supply chain in practice, but most of them are based on the cognition of individual enterprises, which is not universal.

\subsection{Research Trends of Domestic Smart Supply Chain}

The concept of "smart supply" was first proposed by Dr. Luo Gang of Fudan University in 2009 at the Shanghai Conference on integration of informatization and industry. After that, scholars began to pay more and more attention to the intelligent supply chain. Zhai Dufeng (2011) believed that the intelligent supply chain is to embed the intelligent information network technology into the supply chain, realize the high-level integration of information technology, and build a networked, information-based and intelligent supply chain network. Zhang Yuchuan (2012) believes that smart supply chain is to use advanced technologies such as Internet of things and big data to manage all enterprises and their business behaviors in the supply chain by intelligent means, so as to realize the smart operation of the supply chain. Liu Zhigang (2015) believed that "smart supply chain" is an integrated system of intelligence, networking and automation, which is constructed by applying the innovation results of Internet of things and artificial intelligence, combining with the theory, method and technology of modern supply chain management, to better grasp the relevant information of upstream and downstream enterprises, and to realize seamless connection of logistics, information flow and capital flow. Zhou Yongsheng (2015) described the characteristics and development direction of smart supply chain, and proposed to solve the constraints of supply chain from various aspects. Song Hua (2015) explored theoretically the core of "Internet plus", which is to promote the supply chain transformation of the three industries and realize the intelligent supply chain. The innovation of smart supply chain can be reflected in three key elements of Supply Chain Management: Six ability systems formed on the elements; information governance constructed on the structure; intelligent decision-making, 
operation visualization, Organization Ecology and element integration realized on the process. Based on the above scholars' research, scholars basically believe that intelligent supply chain needs to rely on all kinds of advanced science and technology, so that members of the supply chain can achieve seamless docking in information flow, logistics, capital flow and other aspects, and realize the complete sharing of information, so as to achieve the intellectualization, networking and informatization of the supply chain.

\subsection{Literature Review}

With the extensive and in-depth application of cloud computing, artificial intelligence and other information technologies, the supply chain is deeply integrated with the Internet and the Internet of things, and supply chain management begins to enter a new stage of intelligent supply chain. However, the research of smart supply chain is still in its infancy, and the existing research tends to be fragmented.

First, at present, the understanding of smart supply chain from all walks of life is not unified. Compared with the developed countries, our country has no deep understanding of the essence of smart supply chain, some case studies cannot form an effective discipline system and practical guidance, so it is urgent to build a theoretical system.

Second, the construction of smart supply chain system in China and our province is still in the exploratory stage, with weak foundation. From the overall situation of supply chain system construction in China, problems such as inadequate understanding of smart supply chain, lack of smart supply chain strategy, low level of logistics informatization, large number of information islands, lack of professional talents are still outstanding, lack of systematic policy recommendations, and cannot effectively guide the implementation of innovation, development and application of supply chain.

Thirdly, the theoretical research of smart supply chain management is mostly limited to the micro field of a certain industry or a certain link of the supply chain, which has not really combined the supply side reform and the construction of smart supply chain system in China. More literatures use the general theories and tools of "Internet +", big data, artificial intelligence and other information technologies to describe the basic idea of smart supply chain. They do not systematically plan the smart supply chain system and implementation roadmap of key industries, which easily leads to narrow research conclusions that only trees and forests are seen.

\section{Construction of smart supply chain system to promote the quality development of economy in Guangdong, Hong Kong and Macao}

\subsection{Construction Ideas of Smart Supply Chain System}

Supply chain is an organization form which is oriented by customer demand, aims at improving quality and efficiency, and integrates resources to realize the whole process of product design, procurement, production, sales, service and other efficient collaboration. With the development of information technology, supply chain has developed to a new stage of intelligent supply chain, which is deeply integrated with Internet and Internet of things. In order to accelerate the innovation and application of supply chain, promote the innovation of industrial organization mode, business mode and government governance mode, and promote the supply side structural reform of Guangdong Hong Kong Macao Bay area. So this article has carried on the related research. In the process of demonstration, the overall research framework of "four in one" is creatively established, and the research is carried out according to the logical progressive order. This paper mainly analyzes the innovation and application of the smart supply chain system of Guangdong, Hong Kong and Macao in the supply side structural reform process through four key contents, that is, the key contents from 1 to 4 are respectively reflected in the new technology, new concept, new pattern and new mode of the smart supply chain construction system.

\subsection{Construction Path of Smart Supply Chain System to Promote High-quality Economic Development in Guangdong, Hong Kong and Macao}

Based on the background of supply side structural reform, this study aims to build a smart supply chain system in Guangdong, Hong Kong and Macao. The construction path is as follows:

1. (New Technology) construction foundation: Construction of intelligent supply chain system from the perspective of informatization

Based on the perspective of information technology, this paper gives the planning path of the construction of intelligent supply chain system, which mainly embodies the new technologies in the intelligent supply chain. The core content of the construction includes: first, strengthen the macro coordination and functional integration of logistics infrastructure in planning. Make the spatial layout of logistics infrastructure more reasonable, function more perfect, and gradually improve the support ability of various transportation service modes to logistics infrastructure, the operation and network service ability of logistics infrastructure, and the informatization level of logistics infrastructure. Second, we should build the core supporting technology 
of smart supply chain, namely, the research of credit supply chain based on the block chain; the research of Intelligent Supply Chain Decision Platform based on artificial intelligence; and the research of intelligent supply chain collaboration technology based on "Internet + ".

2. (new idea) green system: Construction of smart supply chain system from the perspective of ecology

It mainly embodies the "green" concept in the smart supply chain, and constructs the smart supply chain system construction based on the ecological perspective. The core content of the construction includes: first, the construction of green manufacturing supply chain system. Promote the green management of the whole life cycle of products, and carry out the green supply chain management demonstration in the automobile, electrical electronics, communication, and large complete equipment and machinery industries. Strengthen the green supervision of the supply chain, establish a unified green product standard, certification and identification system, encourage the purchase of green products and services, actively support the green industry, and promote the formation of a green manufacturing supply chain system. Second, actively promote the green logistics system. Advocate the concept of green consumption and cultivate green consumption market. We will encourage the dissemination of energy-saving technologies in the circulation sector and accelerate the upgrading of energy-saving facilities and equipment. Strengthen the research and application of new technology and equipment of green logistics, and establish a green logistics system. Third, establish reverse logistics system. Establish a platform for recycling waste resources based on the supply chain, and build an online waste and renewable resources trading market. Focus on Electrical and electronic products, automobile products, tires, batteries and packaging products, optimize the layout of reverse logistics outlets in the supply chain, and promote the development of product recycling and remanufacturing.

3. (new pattern) global vision: Construction of smart supply chain system from the perspective of openness

It mainly embodies the concept of "opening" and "sharing" in the smart supply chain, and constructs the smart supply chain system based on the perspective of globalization. The core contents include: first, how to integrate Guangdong, Hong Kong and Macao into the global supply chain network. One belt, one road, one information platform and other infrastructure will be built to promote interconnection and interconnection. We will promote international production capacity and equipment manufacturing cooperation, promote the construction of border economic cooperation zones, cross-border economic cooperation zones and overseas economic and trade cooperation zones, encourage enterprises to deepen foreign investment cooperation, and establish a localized supply chain system. Second, how to improve the security level of global supply chain. Enterprises should establish a global supply chain risk early warning system for important resources and products, and improve the level of global supply chain risk management by using two markets and two resources. Formulate and implement the national supply chain security plan, establish the global supply chain risk early warning evaluation index system, improve the global supply chain risk early warning mechanism, and improve the global supply chain risk prevention and control ability. Thirdly, Guangdong, Hong Kong, Macao and Dawan District participate in the formulation of global supply chain rules. Rely on the global supply chain system, promote the inclusive and shared development of different countries and regions, and promote the establishment of new global economic and trade rules conducive to improving the supply chain interest linkage mechanism.

4. (new model) key industries: Construction and implementation roadmap of innovative smart supply chain system

It mainly constructs the new mode in the intelligent supply chain, and gives the planning path for the construction of the intelligent supply chain system of key industries based on the innovative perspective. The main contents of the construction include: first, to promote the integration of primary, secondary and tertiary industries in rural areas, that is, to innovate the organization system of agricultural industry and to promote various forms of agricultural moderate scale operation; Improve the scientific level of agricultural production, promote the construction of agricultural supply chain information platform, strengthen the connection between production and marketing, increase the supply of green and highquality agricultural products, encourage the development of agricultural productive services; Improve the traceability of quality and safety, strengthen the construction of cold chain facilities and standardization of agricultural products and food; Establish traceability mechanism of quality and safety of important products based on supply chain. Second, promote manufacturing collaboration, service and intelligence. That is to promote supply chain collaborative manufacturing and improve the whole chain supply chain system from R \& $\mathrm{D}$ design, production and manufacturing to after-sales service; Develop service-oriented manufacturing, build a number of public service platforms for service-oriented manufacturing, develop the productive service industry based on supply chain, and promote the transformation from manufacturing supply chain to industrial service supply chain; Promote the visualization and intelligence of manufacturing supply chain and improve the ability of agile manufacturing. Third, improve the level of circulation modernization. That is to promote the innovation and transformation of circulation, apply the concept and technology of supply chain, and improve the intelligent level of circulation supply chain; Promote the deep integration of circulation and production, and build a supply chain collaboration platform; Guide the transformation of traditional circulation enterprises to supply chain service enterprises, and vigorously cultivate new supply chain service enterprises. 


\section{Conclusion}

To sum up, through the research of this paper, we hope to form a batch of new technologies and models for supply chain development suitable for Guangdong, Hong Kong and Macao Bay area, and basically form a smart supply chain system covering key industries in the province. Making smart supply chain plays a significant role in promoting cost reduction and efficiency increase, supplies and demands matching and industrial upgrading, and becomes an important support for supply side structural reform. This study will provide theoretical reference for Guangdong Province and Guangdong Hong Kong and Macao Bay area to cultivate global supply chain leading enterprises, and ensure the supply chain competitiveness of key industries to enter the forefront of the world, so as to make Guangdong Hong Kong and Macao Bay area become an important center of global supply chain innovation and application.

\section{Acknowledgment}

This work is financially sponsored Guangdong Education Science Planning Project, building an efficient and intelligent supply chain system to promote the highquality economic development of Guangdong-Hong Kong-Macao Greater Bay Area (2019GXJK072).

\section{References}

1. Zhang Ying. Thinking on the framework of regional governance mechanism of urban agglomerations in
Guangdong, Hong Kong and Macao: from the perspective of government governance [J]. Journal of Shanghai University of foreign trade and economic cooperation, 2020,27 (02): 103-110

2. Cai Lingsha. Research on dual learning, knowledge integration and FDI performance [J]. Soft science, 2020 (02): 59-65

3. Wang Wei, Zhu Xiaochuan, Liang Xia. Analysis on the evolution and influencing factors of innovation spatial pattern in Guangdong, Hong Kong and Macao Bay area and expansion area [J]. Urban development research, 2020,27 (02): 16-24

4. Zhong Shichuan, Mao Yanhua. Study on the measurement and characteristics of productivity of urban agglomerations in Guangdong, Hong Kong and Macao [J]. Science research, 2020,38 (02): 252$258+356$

5. Shan Jingjing, Zhang Zhuoqun. Research status, problems and Countermeasures of integration development of Guangdong, Hong Kong and Macao Bay Area [J]. Journal of Beijing University of Technology (SOCIAL SCIENCE EDITION): 1-8

6. Qin Chenglin, pan Dandan. Industrial structure upgrading and economic performance analysis of Guangdong Hong Kong Macao Bay Area [J]. Economic and management review, 2020 (01): 137147

7. Liu Yi, Wang Yun, Yang Yu, Ma Li. Regional integration and interaction in Guangdong Hong Kong Macao Bay Area [J]. Journal of geography, 2019,74 (12): 2455-2466 